\title{
Using Dynamic Changes of Chlorophyll Fluorescence in Arabidopsis thaliana to Evaluate Plant Immunity-Intensifying Bacillus spp. Strains
}

\author{
Yi-Hsin Wang, ${ }^{1}$ I-Ling Lai, ${ }^{2}$ Jing-Lin Zheng, ${ }^{1}$ and Yi-Hsien Lin ${ }^{1, \dagger}$ \\ ${ }^{1}$ Department of Plant Medicine, National Pingtung University of Science and Technology, Pingtung, Taiwan \\ ${ }^{2}$ Graduate Institute of Bioresources, National Pingtung University of Science and Technology, Pingtung, Taiwan \\ Accepted for publication 7 May 2019.
}

ABSTRACT

\begin{abstract}
The integral defense responses of plants triggered by the small molecules of plant pathogens are regarded as plant immunity. The pathogen-associated molecular pattern-triggered immunity (PTI) occurs on the recognition of a pathogen by receptors on plant cell surfaces as an infection begins. During the activation of PTI, the effectiveness of a plant's photosynthetic system may be altered. In this study, chlorophyll fluorescence was used to assay the dynamic changes of PTI. When we used flg22 2 Pst as an elicitor, we found that the photosynthetic electron transport rate (ETR) of Arabidopsis thaliana Col-0 was significantly decreased at 2,4 , and $24 \mathrm{~h}$ on treatment with a PTI-intensifying protein, plant ferredoxin-like protein (PFLP). In addition, this reduction in the photosynthetic ETR was also carried out with a PTI-intensifying Bacillus amyloliquefaciens strain, PMB05, on the induction of flg22Pst. The disease resistance against bacterial soft rot caused
\end{abstract}

by Pectobacterium carotovorum subsp. carotovorum (Pcc) was still enhanced by PMB05. Interestingly, among the eight tested Bacillus species strains, the PTI triggered by $\mathrm{HrpN}_{\mathrm{Pcc}}$ from $P$. carotovorum subsp. carotovorum exhibited an ETR that was significantly decreased by $\mathrm{PMB} 05$. Furthermore, this decrease was consistent with rapid $\mathrm{H}_{2} \mathrm{O}_{2}$ generation and callose deposition triggered by $\mathrm{HrpN}_{\mathrm{Pcc}}$ and the disease resistance against bacterial soft rot. Taken together, such results led us to conclude that the assay based on the ETR established in this study can be used as a model for evaluating the effectiveness of plant immunity-intensifying microbes for controlling plant diseases.

Keywords: Bacillus amyloliquefaciens, chlorophyll fluorescence, electron transport rate, plant ferredoxin-like protein, plant immunity
Protecting plants against bacterial diseases by increasing their defense responses is one strategy with potential agricultural applications. Relatedly, a response of pattern recognition receptors on the surfaces of plant cells to the small molecules of pathogens termed pathogen-associated molecular pattern (PAMP)-triggered immunity (PTI) has previously been documented. Previous studies have further shown that intensifications of PTI through ectopically plant ferredoxin-like protein (PFLP) led plants to increase their disease resistance (Hong et al. 2018; Su et al. 2014). Such increased disease resistance has been successful in controlling bacterial wilt on tomatoes and bananas, bacterial soft rot on tomatoes and orchids, bacterial blight on rice, and Fusarium wilt on bananas (Huang et al. 2007; Namukwaya et al. 2012; Tang et al. 2001; Yip et al. 2007, 2011). Similarly, PTI intensified by the Bacillus amyloliquefaciens strain PMB05 has been shown to provide excellent disease resistance against bacterial wilt on black rot on cabbages (Li'aini et al. 2017).

The observation of rapid reactive oxygen species (ROS) production and callose deposition or the analysis of the expression of defense-related genes can be used as indicators during the occurrence of PTI (Lu et al. 2011; Luna et al. 2011; Nie et al. 2017; Su et al. 2014); however, the examination of these parameters is destructive and cannot be used to assess dynamic changes of immune responses. Reports have shown that the occurrence of plant immune responses can be regulated by the efficacy of the

†Corresponding author: Y.-H. Lin; yhlin@mail.npust.edu.tw

Funding: This work was supported by grants to Yi-Hsien Lin from the Ministry of Science and Technology, Taiwan (MOST 105-2628-B-020-002-MY3).

*The $\boldsymbol{e}$-Xtra logo stands for "electronic extra" and indicates that four supplementary figures are published online.

The author(s) declare no conflict of interest.

(C) 2019 The American Phytopathological Society photosynthetic systems of the plants in question. In addition, the photosynthetic system of a plant is one of the systems through which the plant exhibits responsiveness in terms of ROS generation (Asada 1999; Lamb and Dixon 1997; Sierla et al. 2013). Recent studies have demonstrated that the activation of PTI signals is associated with the expression of genes and nonphotochemical quenching (NPQ) in chloroplasts (Göhre et al. 2012; Nomura et al. 2012). Therefore, the crosstalk between the dynamic changes in the chlorophyll fluorescence of a photosynthetic system and the intensification of PTI could be assessed to establish a model for evaluating possible PTI-intensifying microbes.

In this study, we used chlorophyll fluorescence analysis, as well as evaluations of rapid $\mathrm{H}_{2} \mathrm{O}_{2}$ generation and callose deposition, of A. thaliana in the presence of PFLP or B. amyloliquefaciens PMB05 on the activation of $\mathrm{flg} 22_{\mathrm{Pst}}$. Meanwhile, the effect of PTIintensifying PFLP and PMB05 on the disease resistance to bacterial soft rot caused by Pectobacterium carotovorum subsp. carotovorum (Pcc) was also analyzed because the HrpN from P. carotovorum subsp. carotovorum is a PAMP that elicits defense responses (Kariola et al. 2003). Moreover, the effects of other Bacillus spp. strains in the presence of $\mathrm{HrpN}$ from strain Ecc17 of $P$. carotovorum subsp. carotovorum were also assessed. We concluded that the chlorophyll fluorescence conditions that we developed can be used as a new model for evaluating PTI-intensifying microbes that potentially could be used to control bacterial soft rot.

\section{MATERIALS AND METHODS}

Growth conditions of plants and bacteria. The A. thaliana ecotype Columbia (Col-0) was used in this study. Seeds of the plant were sown in peat moss. One week later, the germinated seedlings were transplanted to individual pots for 3 weeks. All the plants were grown in a growth chamber (Hipoint, Kaohsiung City, Taiwan) with a growth temperature of $22^{\circ} \mathrm{C}$, a light condition of $16 \mathrm{~h}$ light $/ 8 \mathrm{~h}$ darkness, and an illumination intensity of $200 \mu \mathrm{mol} \mathrm{m} \mathrm{m}^{-2} \mathrm{~s}^{-1}$. The bacterial soft rot pathogen, $P$. carotovorum subsp. carotovorum 
strain Ecc17, was also used in this study. This bacterial strain was cultured on agar plates in nutrient broth (Becton, Dickinson and Company, Franklin Lakes, NJ) at $28^{\circ} \mathrm{C}$ for $24 \mathrm{~h}$ for further experiments. To express the PFLP and HrpN protein, the Escherichia coli BL21 strains containing the pET-PFLP (OEPFLP) (Lin et al. 2011) and pET-HrpN-Ecc17 (OE-HrpN17), respectively, were used. These strains were cultured in LuriaBertani (LB) broth supplemented with ampicillin at $100 \mu \mathrm{g} / \mathrm{ml}$ at $37^{\circ} \mathrm{C}$ for 16 to $18 \mathrm{~h}$. Eight Bacillus spp. strains (PMB03, PMB04, PMB05, DR81, DR237, DR243, DR244, and DR258) were assayed in this study. A single colony of each strain was cultured in nutrient broth medium at $28^{\circ} \mathrm{C}$ for $24 \mathrm{~h}$. After the culture was centrifuged at $8,000 \times g$ for $10 \mathrm{~min}$, each bacterial suspension was prepared and adjusted to $\mathrm{OD}_{620}$ at 0.3 with sterilized distilled water before subsequent experiments.

Preparation of bacterial PAMP and PFLP. To induce basal PAMP-triggered immunity, the flg22 $2_{\mathrm{Pst}}$ from Pseudomonas syringae pv. tabaci (Felix et al. 1999) and HrpN from P. carotovorum subsp. carotovorum strain Ecc17 were used. The flg22 $2_{\text {Pst }}$ was synthesized by LifeTien LCC (South Plainfield, NJ) and then prepared with $25 \mathrm{mM}$ Tris- $\mathrm{HCl}$ buffer ( $\mathrm{pH} 7.5$ ) to produce a stock solution. The stock solution was applied in all experiments to $0.5 \mu \mathrm{M}$ of final concentration in this study. To obtain the HrpN and PFLP, OE-HrpN17 and OE-PFLP cultured in LB broth were induced with $1 \mathrm{mM}$ of isopropyl- $\beta$-D-thiogalactopyranoside (IPTG). Subsequently, the cells were disrupted and purified by using a NiNTA Spin Kit according to the manufacturer's instructions (Qiagen, Venlo, The Netherlands). Both the HrpN and PFLP were applied at $0.5 \mathrm{mg} / \mathrm{ml}$ of final concentration in all the assays.

Measurement of chlorophyll fluorescence. To investigate the spatial heterogeneity and temporal changes of photosynthetic performance in the presence of PAMPs and PFLP or the antagonistic strain PMB05, the methods of chlorophyll fluorescence imaging were applied as in previous research (Song et al. 2016; Xu and Zhou 2006) with slight modifications. Briefly, chlorophyll fluorescence parameters were measured around the inoculation site in the leaves using an imaging chlorophyll fluorometer (Imaging-PAM m-series; Walz, Effeltrich, Germany). The plants were then dark-adapted after inoculation for more than $30 \mathrm{~min}$. The image of the minimum chlorophyll fluorescence value $F_{0}$ was acquired using $0.5 \mu \mathrm{mol}$ photons $\mathrm{m}^{-2} \mathrm{~s}^{-1}$ light in dark adaptation and the maximum fluorescence in the dark-adapted state, $F_{\mathrm{m}}$, was determined by applying a short saturated blue pulse light $\left(8,000 \mu \mathrm{mol}\right.$ photons $\left.\mathrm{m}^{-2} \mathrm{~s}^{-1}, 0.8 \mathrm{~s}\right)$ after $30 \mathrm{~min}$. Based on the $F_{0}$ and $F_{\mathrm{m}}$ values, the images of the potential photosystem II (PSII) light efficiency $F_{\mathrm{v}} / F_{\mathrm{m}}$ for each image pixel were derived as $\left(F_{\mathrm{m}}-\right.$ $\left.F_{0}\right) / F_{\mathrm{m}}$ ) (Genty et al. 1989) using the appropriate software (Imaging Win version 2.32; Walz). The decrease of $F_{\mathrm{v}} / F_{\mathrm{m}}$ is used to indicate the damage of PSII reaction center. After dark adaptation, the light response curve of the chlorophyll fluorescence was determined directly. The actinic light was turned on and increased in a stepwise manner from a low light level, a photosynthetic photon flux (PPF) of $11 \mu \mathrm{mol}$ photons $\mathrm{m}^{-2} \mathrm{~s}^{-1}$, to a high light level of PPF $701 \mu \mathrm{mol}$ photons $\mathrm{m}^{-2} \mathrm{~s}^{-1}$, with the each of the 15 light levels maintained for $20 \mathrm{~s}$. At the end of the period for each light level, a saturated pulse was applied to get the maximum fluorescence image $F_{\mathrm{m}}$ ', while the basal image at the time was $F$, such that the effective quantum yield $\left(\mathrm{Y}_{\text {(II) }}\right)$ of the light level was calculated as $\left(F_{\mathrm{m}}{ }^{\prime}-F\right) / F_{\mathrm{m}}$ '. For each light level, the electron transport rate (ETR) was calculated with $0.5 \times \mathrm{Y}(\mathrm{II}) \times \mathrm{PPF} \times 0.84$ (Cornic and Baker 2012; Ehleringer 1981) to indicate the efficiency of photosynthetic light reaction system. The quantum yield of nonregulated energy dissipation of PSII $\left(\mathrm{Y}_{(\mathrm{NO})}\right)$ was calculated as $F / F_{\mathrm{m}}$, and the quantum yield of regulated energy dissipation of PSII ( $\mathrm{Y}_{(\mathrm{NPQ})}$ ) was calculated as $F / F_{\mathrm{m}}{ }^{\prime}-F / F_{\mathrm{m}}$ (Klughammer and Schreiber 2008; Kramer et al. 2004). $\mathrm{Y}_{(\mathrm{NPQ})}$ and $\mathrm{Y}_{(\mathrm{NO})}$ comprised the ratio of light energy not into the photochemical reaction, hence the photosynthetic process. $\mathrm{Y}_{(\mathrm{NPQ})}$ denoted the part plant could convert the excess energy to heat through xanthophyll or lutein cycle, whereas $\mathrm{Y}_{(\mathrm{NO})}$ denoted the part of energy potentially causing oxidative damage to PSII. The average value of all the parameters inside the area of each inoculation site was circled and calculated using the same software. Each treatment was carried out with six inoculation sites in one plant, and values from 10 plants were collected as repeats. The data for each light level were analyzed by Tukey's honestly significant difference (HSD) test at $5 \%$ significance level.

Rapid $\mathrm{H}_{2} \mathrm{O}_{2}$ generation assay. To assess whether the rapid generation of $\mathrm{H}_{2} \mathrm{O}_{2}$ was intensified by PFLP or B. amyloliquefaciens PMB05 during the activation of PAMP-triggered immunity (PTI), Arabidopsis leaves were stained and observed by fluorescence microscopy at $1 \mathrm{~h}$ postinfiltration ( $\mathrm{Su}$ et al. 2014). The leaves of the Arabidopsis plants were stained with $20 \mu \mathrm{M} 2^{\prime}, 7^{\prime}$-dichlorodihydrofluorescein diacetate (Molecular Probes, Eugene, OR) in PBS buffer. The leaves were reacted under dark for $15 \mathrm{~min}$ and were then washed with PBS buffer three times. The leaves were then observed under a fluorescence microscope with an excitation at 465 to $495 \mathrm{~nm}$ and emission at 515 to $555 \mathrm{~nm}$ filter set (Leica, Wetzlar, Germany). The strength of $\mathrm{H}_{2} \mathrm{O}_{2}$ generation was determined using the Image $\mathbf{J}$ software (https://imagej.nih.gov/ij/) to measure the fluorescent intensity under a consistent threshold (Rasband 1997-2016). Data for each treatment were collected from 10 samples of individual leaves as repeats. The data were analyzed by Tukey's HSD test at $5 \%$ significance level.

Callose deposition assay. To observe the intensification of callose deposition, the Arabidopsis leaves were stained and observed at $8 \mathrm{~h}$ postinfiltration. Before observation, the collected leaves were soaked in $95 \%$ ethanol overnight and further stained with $0.01 \%$ aniline blue (Sigma, USA) in $0.1 \mathrm{M}$ phosphate buffer ( $\mathrm{pH} \mathrm{8)}$ for $2 \mathrm{~h}$ (Hong et al. 2018). The leaves were then observed under a fluorescence microscope with an excitation at 340 to $380 \mathrm{~nm}$ and emission at 400 to $425 \mathrm{~nm}$ filter set (Leica). The strength of the callose deposition was determined using the Image $\mathbf{J}$ software (https://imagej.nih.gov/ij/) to measure the fluorescent intensity under a consistent threshold (Rasband 1997-2016). Data for each treatment were collected from 10 samples of individual leaves as repeats. The data were analyzed by Tukey's HSD test at $5 \%$ significance level.

Disease severity assay. A disease severity assay of bacterial soft rot on Arabidopsis plants was performed with the inoculation applied to detached leaves ( $\mathrm{Su}$ et al. 2014). Briefly, bacterial suspensions of $P$. carotovorum subsp. carotovorum strain Ecc17 were prepared in sterilized distilled water and adjusted to 0.3 at $\mathrm{OD}_{600}$. Then, the detached leaves of Arabidopsis plants were placed and vacuumed in a 100 -fold dilution of bacterial suspension at $200 \mathrm{~mm} \mathrm{Hg}$ for $15 \mathrm{~min}$. The inoculated leaves were incubated in a growth chamber at $22^{\circ} \mathrm{C}$. The disease severity was calculated based on the disease indexes of soft rot symptoms rated from 0 to 4 (0: no symptoms; 1 : watery or soft rot area ratio of 0 to $25 \% ; 2$ : soft rot area ratio of 25 to $50 \%$; 3 : soft rot area ratio of 50 to $75 \%$; 4 : soft rot area ratio of 75 to $100 \%$ ) at $48 \mathrm{~h}$ postinoculation. Data regarding the disease severity of each treatment were collected from five leaves; three replications of each treatment were performed for statistical analysis.

\section{RESULTS}

Dynamic changes of chlorophyll fluorescence in PFLPintensified PTI triggered by flg22 $2_{\text {Pst }}$. To assess the effect of PFLP in terms of intensifying PTI responses, flg $22_{\text {pst }}$ was first used as a PAMP for analysis. There were no significant differences in the potential PSII light efficiency $F_{\mathrm{v}} / F_{\mathrm{m}}$ of the leaves when treated with Tris, flg22 $2_{\text {Pst }}$, PFLP, or flg22 $2_{\text {Pst }}$ with PFLP at 0, 2, 4, and $24 \mathrm{~h}$ Supplementary Fig. S1. The ETR obtained from the leaves treated with Tris, PFLP, or flg22 $2_{\text {sst }}$ alone was gradually increased with the light levels (PPF), and there were no significant differences in the ETR values for these three treatments at 0, 2, 4, and $24 \mathrm{~h}$ (Fig. 1). 
However, the increases in ETR for treatment with flg22 $2_{\mathrm{Pst}}$ and PFLP was lower than that for the other three treatments from the second hour onward, with the difference continuing to be significant at 4 and even $24 \mathrm{~h}$. Meanwhile, although the quantum yield of regulated energy dissipation of PSII ( $\mathrm{Y}_{(\mathrm{NPQ})}$ ) was increased for each of the four treatments with greater light intensities, with no significant difference between the treatments at 2 and $4 \mathrm{~h}$, the $\mathrm{Y}_{(\mathrm{NPQ})}$ of the treatment with a mixture of flg $22_{\mathrm{Pst}}$ and PFLP was significantly lower than those for the other three treatments at the light levels between 50 and $350 \mu \mathrm{mol} \mathrm{m} \mathrm{m}^{-2} \mathrm{~s}^{-1}$ (Fig. 2). The quantum yield of nonregulated energy dissipation of PSII $\left(\mathrm{Y}_{(\mathrm{NO})}\right)$ showed patterns similar to those of the $\mathrm{Y}_{(\mathrm{NPQ})}$ responses. Specifically, there were no significant differences in the dynamic changes between the four treatment groups at 2 and $4 \mathrm{~h}$ after inoculation Supplementary Fig. S2. However, the $\mathrm{Y}_{(\mathrm{NO})}$ of the leaves treated with the flg22 $2_{\text {Pst }}$ and PFLP mixture was significantly higher than those of the control group leaves and those treated with PFLP or flg $22_{\mathrm{Pst}}$ alone.

Dynamic changes of chlorophyll fluorescence in B. amyloliquefaciens PMB05-intensified PTI triggered by flg22 Pst . To analyze whether the photosynthetic system would be affected by $B$. amyloliquefaciens strain PMB05 during the activation of PTI triggered by flg22 $2_{\mathrm{Pst}}$, the changes in the chlorophyll fluorescence of leaves were measured. As with the results assayed for treatment with PFLP, the $F_{\mathrm{v}} / F_{\mathrm{m}}$ of the leaves exhibited no significant difference among the four treatments at $0,2,4$, and $24 \mathrm{~h}$ Supplementary Fig. S3. The ETR values of the leaves treated with Tris, bacterial suspension of PMB05, or flg22 $2_{\text {Pst }}$ alone also showed no significant differences at 2 and $4 \mathrm{~h}$ postinfiltration, but the leaves inoculated with flg22 2 Pst presented a significantly lower ETR value than those treated with Tris or bacterial suspension of PMB05 alone between 200 and $400 \mu \mathrm{mol} \mathrm{m}^{-2} \mathrm{~s}^{-1}$ of PPF at $24 \mathrm{~h}$ postinfiltration. The ETR values of the leaves infiltrated with the mixture of strain PMB05 and flg22 $2_{\text {Pst }}$ were significantly lower than those of the leaves treated with the other three treatments of more than $400 \mu \mathrm{mol} \mathrm{m} \mathrm{m}^{-2} \mathrm{~s}^{-1}$ of PPF at 2, 4, and $24 \mathrm{~h}$ (Fig. 3). The $\mathrm{Y}_{(\mathrm{NPQ})}$ values of the leaves that received all four treatments increased with increasing light intensity. The $Y_{(\mathrm{NPQ})}$ values of the leaves treated with bacterial suspension of PMB05 or flg22 2 st alone exhibited no significant difference with those of the leaves treated with Tris at $0,2,4$, and $24 \mathrm{~h}$. However, the $\mathrm{Y}_{(\mathrm{NPQ})}$ values of the leaves treated with the mixture of PMB05 and flg22 $2_{\text {Pst }}$ were significantly higher than those of the other three groups at $2 \mathrm{~h}$ under 0 to $200 \mu \mathrm{mol} \mathrm{m} \mathrm{m}^{-2} \mathrm{~s}^{-1}$ of PPF, but then significantly lower at
A
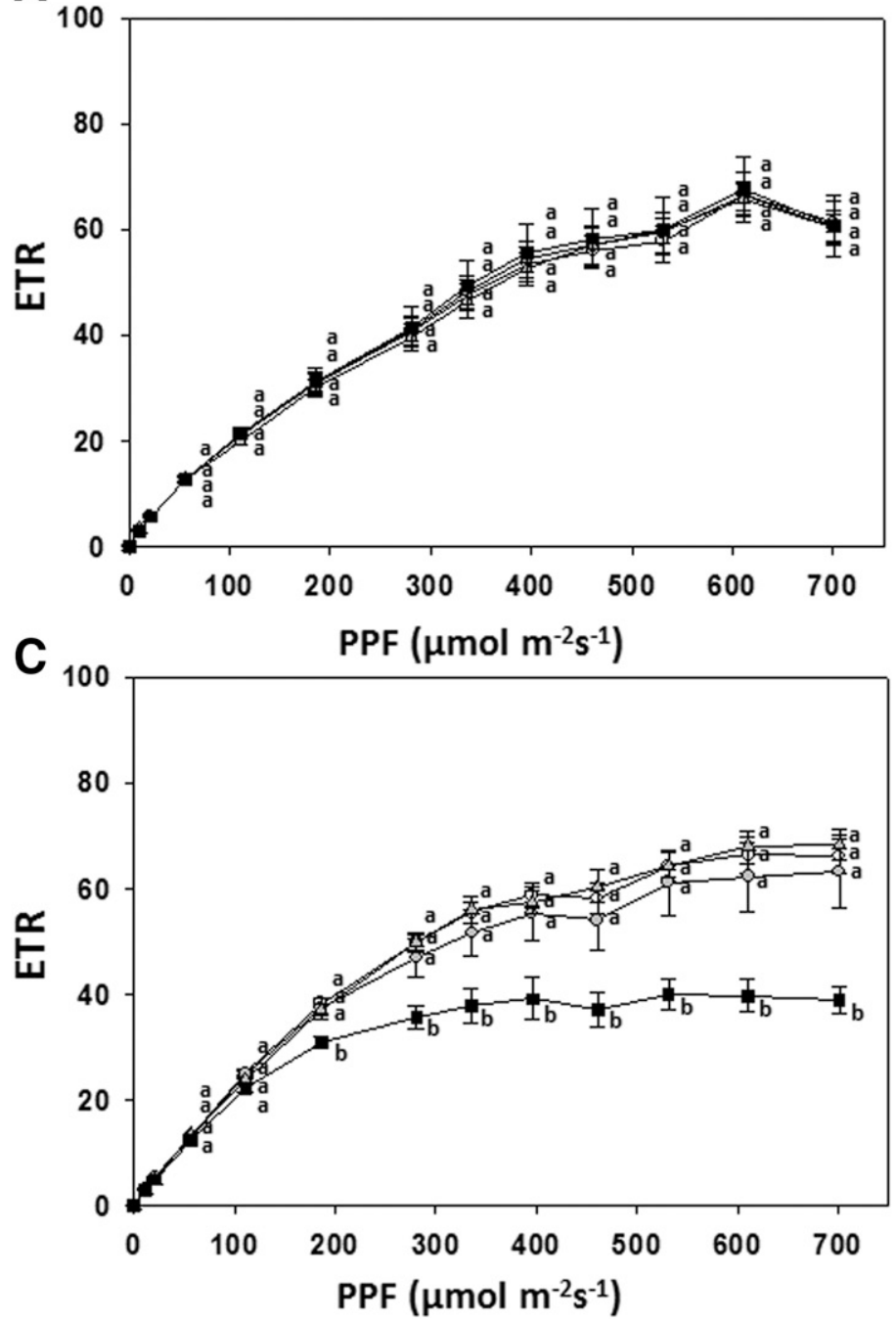

B
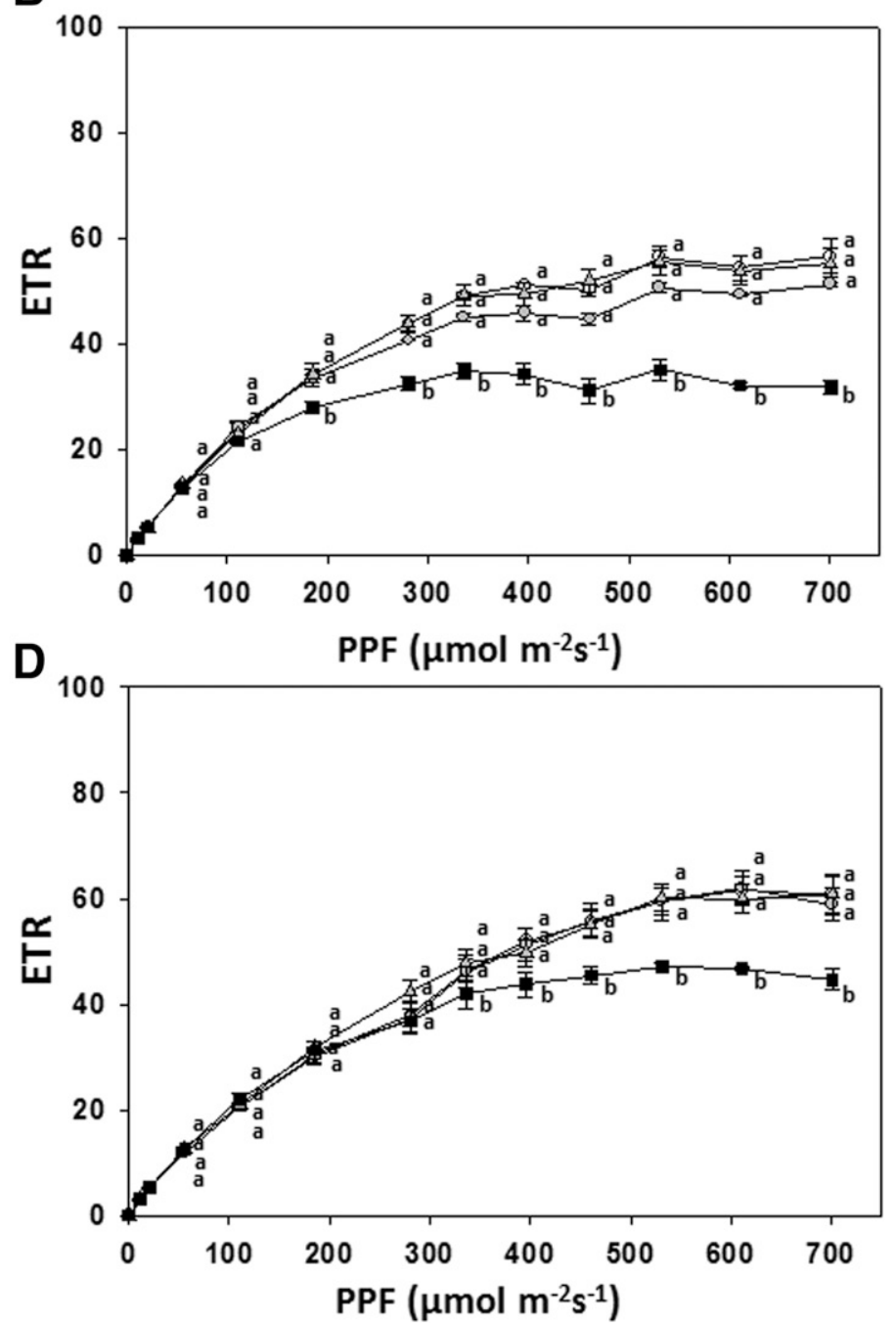

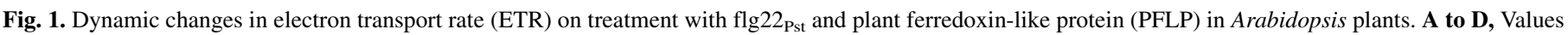

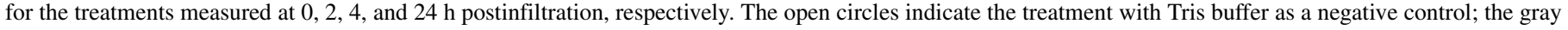

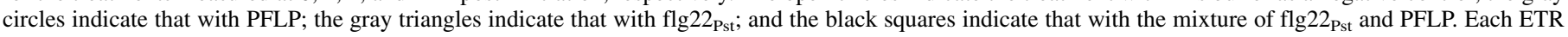

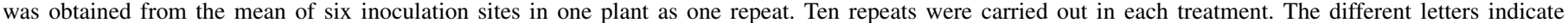
significant differences among the treatments at the same photosynthetic photon flux based on Tukey's honestly significant difference test $(P<0.05)$. 
every light level at 4 and $24 \mathrm{~h}$ after inoculation (Fig. 4). On the other hand, the $\mathrm{Y}_{(\mathrm{NO})}$ responses of the leaves receiving the four treatments were generally very close at $0,2,4$, and $24 \mathrm{~h}$ after inoculation Supplementary Fig. S4. The only exception was that the $\mathrm{Y}_{(\mathrm{NO})}$ values of the leaves treated with Tris, bacterial suspension of PMB05, or flg22 $2_{\text {st }}$ became significantly higher than those of the leaves treated with the mixture of flg22 $2_{\mathrm{Pst}}$ and PMB05 under 0 to $350 \mu \mathrm{mol} \mathrm{m}{ }^{-2} \mathrm{~s}^{-1}$ of PPF at $2 \mathrm{~h}$.

Disease resistance enhanced by PFLP and $B$. amyloliquefaciens PMB05. To confirm that disease resistance was enhanced by PFLP or B. amyloliquefaciens PMB05, the control efficacy of bacterial soft rot was evaluated in A. thaliana. The results showed that the disease severity of Col-0 plants was reduced from 82.5 to $38.8 \%$ by PFLP (Fig. 5A). Further observation of the symptom development of leaves inoculated with Ecc17 alone at 0, 2, 4, and $24 \mathrm{~h}$ indicated that most of the leaves showed more than $3 / 4$ of the soft rot symptoms at $24 \mathrm{~h}$ after inoculation. In contrast, most of the leaves treated with PFLP remained symptomless (Fig. 5B). Similarly, the disease severity of Col-0 plants was reduced from 82.2 to $12.5 \%$ by B. amyloliquefaciens PMB05 (Fig. 5C). Furthermore, most of the leaves treated with PMB05 also exhibited no soft rot symptoms (Fig. 5D).

Effects of Bacillus spp. strains in conjunction with HrpN $_{\text {Pcc-mediated PTI on ETRs. To assay the effects of Bacillus }}$ spp. strains on ETRs also affected by the activation of PTI triggered by distinct PAMP, HrpN $\mathrm{N}_{\mathrm{Pcc}}$ from $P$. carotovorum subsp. carotovorum was used as an elicitor in this assay. The results showed that the ETR was significantly reduced by $\mathrm{HrpN}_{\text {Pcc }}$ from 97.3 to 77.4 and from 97.3 to 78.6 under light levels of 611 and $701 \mu \mathrm{mol} \mathrm{m} \mathrm{m}^{-2} \mathrm{~s}^{-1}$ of PPF, respectively, at $2 \mathrm{~h}$ postinfiltration (Fig. 6). Moreover, the $\mathrm{HrpN}_{\mathrm{Pcc}^{-}}$ mediated ETRs of leaves also treated with $B$. amyloliquefaciens strains PMB03 and PMB05 were significantly reduced to 69.9 and 61.6, respectively, in comparison with those of leaves treated with $\mathrm{HrpN}_{\text {Pcc }}$ alone under $611 \mu \mathrm{mol} \mathrm{m} \mathrm{m}^{-2} \mathrm{~s}^{-1}$ of PPF (Fig. 6A). Meanwhile, the $\mathrm{HrpN}_{\mathrm{Pcc}}$-mediated ETRs of leaves also treated with PMB03 and PMB05 were reduced to 70.4 and 63.5, respectively, under $701 \mu \mathrm{mol}$ $\mathrm{m}^{-2} \mathrm{~s}^{-1}$ of PPF (Fig. 6B). However, the $\mathrm{HrpN}_{\mathrm{Pcc}}$-mediated ETR results of leaves treated with Bacillus spp. strains PMB04, DR81, DR237, DR243, DR244, and DR258 were not altered in comparison with those of leaves treated with $\mathrm{HrpN}_{\mathrm{Pcc}}$ alone at the two different light levels.
A
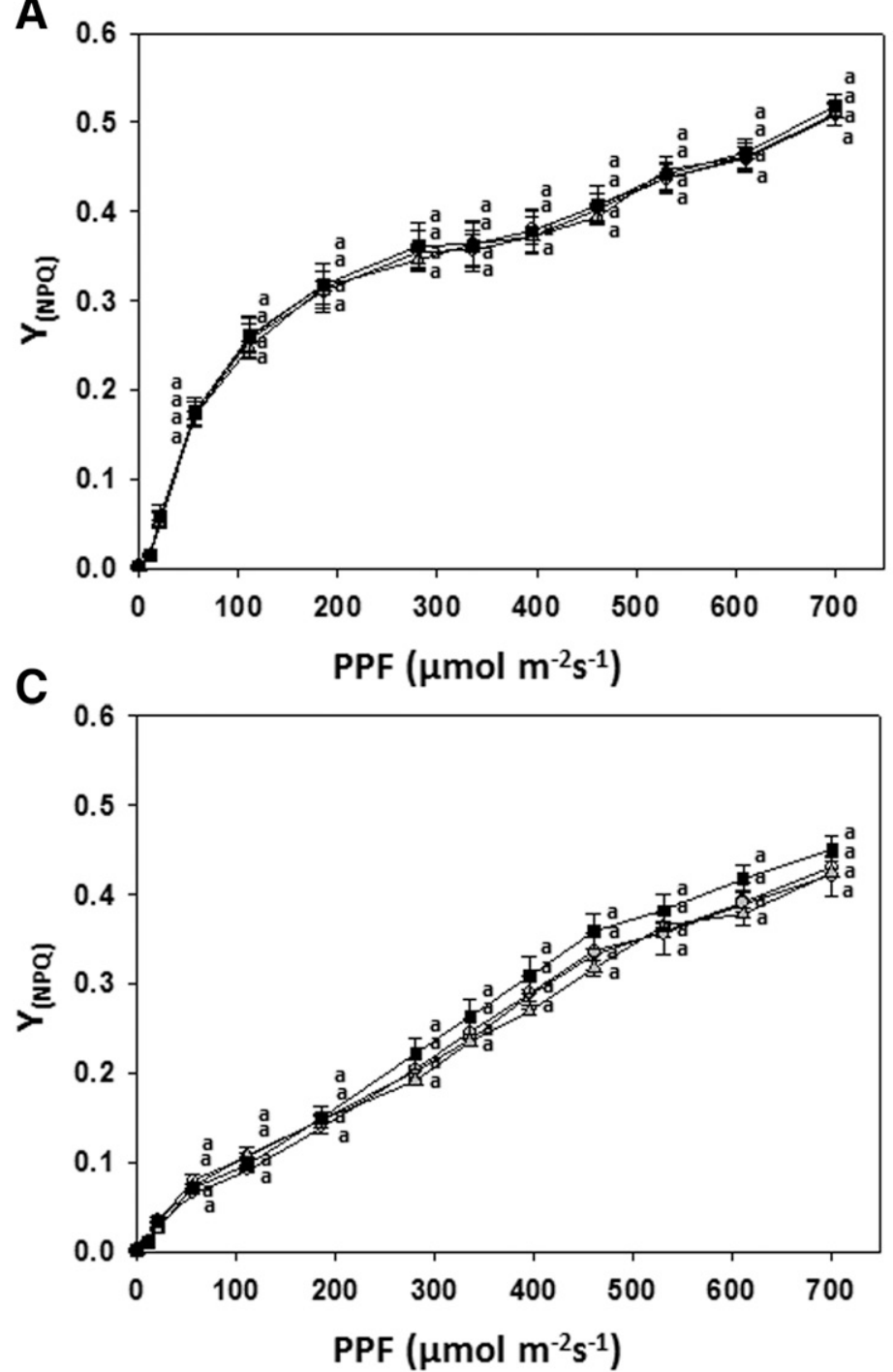

B
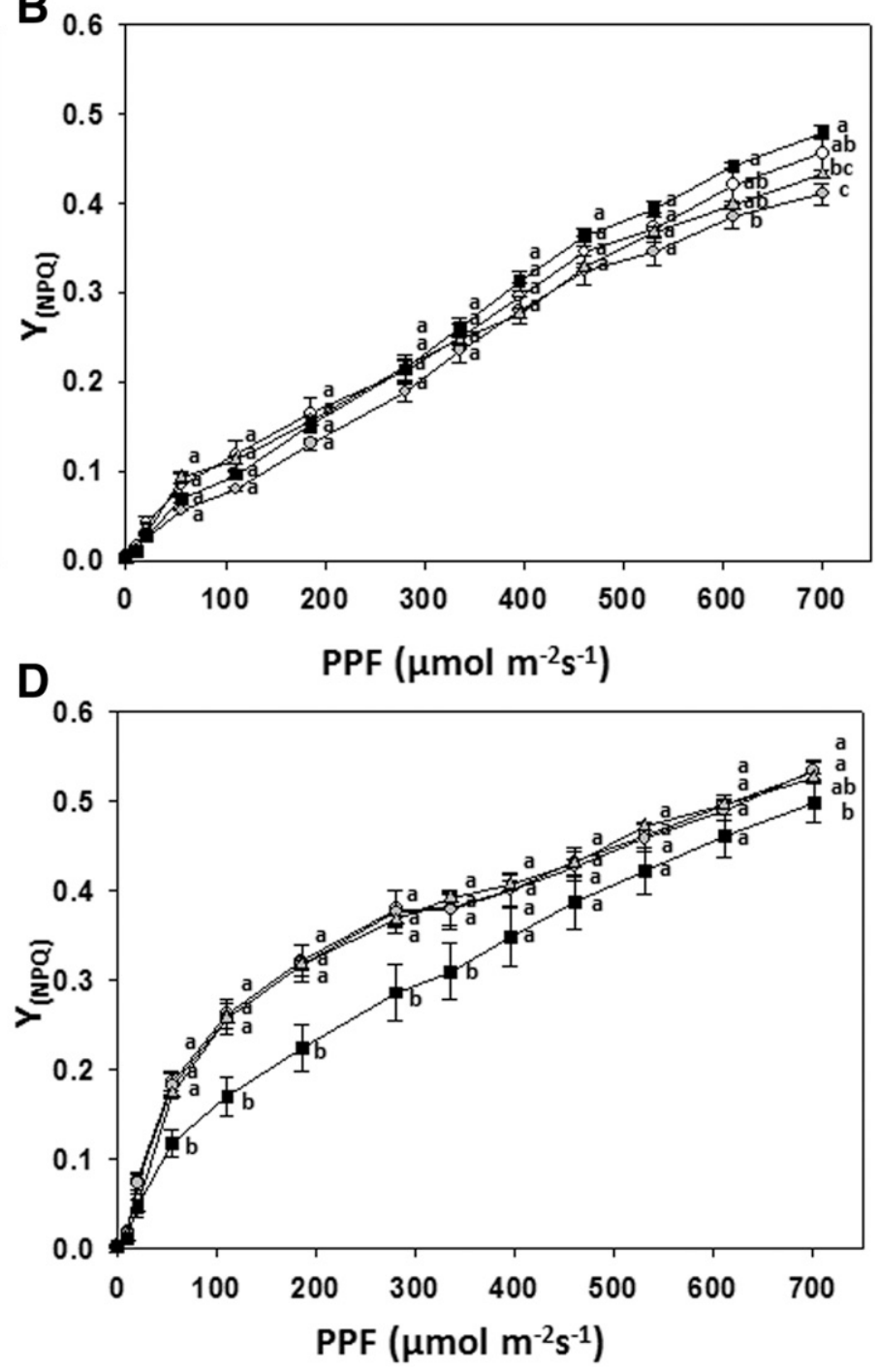

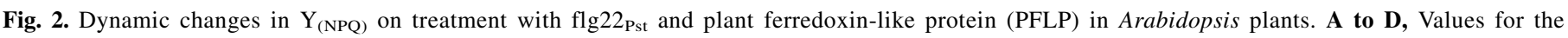

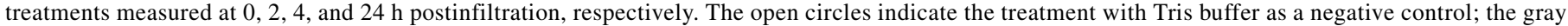

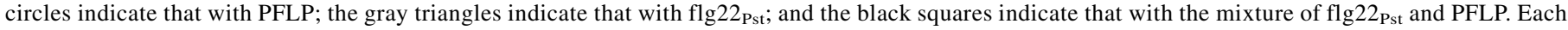

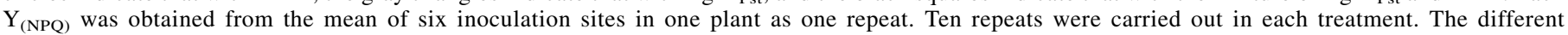

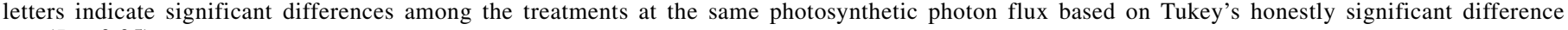
test $(P<0.05)$. 
Effects of Bacillus spp. strains in conjunction with

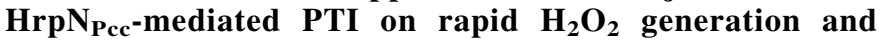
callose deposition. To further analyze the effects of Bacillus spp. strains on $\mathrm{HrpN}_{\mathrm{Pcc}}$-triggered plant immune signals, the rapid $\mathrm{H}_{2} \mathrm{O}_{2}$ generation and callose deposition in Arabidopis leaves were observed. The results revealed that all tested Bacillus spp. strains did not induce the $\mathrm{H}_{2} \mathrm{O}_{2}$ generation while compared with the blank treatment. A small quantity of $\mathrm{H}_{2} \mathrm{O}_{2}$ generation was induced by $\mathrm{HrpN}_{\text {Pcc }}$ alone. More abundant amounts of $\mathrm{H}_{2} \mathrm{O}_{2}$ were generated by $\mathrm{HrpN}_{\mathrm{Pcc}}$-treatments with B. amyloliquefaciens strain PMB03 or PMB05 than by those with other Bacillus spp. strains (Fig. 7A). The $\mathrm{HrpN}_{\text {Pcc }}$-mediated fluorescent intensities of $\mathrm{H}_{2} \mathrm{O}_{2}$ signals were intensified by 3.7 - and 8.6-fold by $B$. amyloliquefaciens strains PMB03 and PMB05, respectively. In contrast, the intensities obtained from the treatments with other Bacillus spp. strains did not show significant differences in comparison with that of treatment with $\mathrm{HrpN}_{\mathrm{Pcc}}$ alone (Fig. 7B). The callose deposition induced by $\mathrm{HrpN}_{\text {Pcc }}$ was observed at $8 \mathrm{~h}$ postinfiltration. Similarly, all tested Bacillus spp. strains did not induce callose deposition while compared with the blank treatment in the infiltration of Arabidopsis leaves. A small amount of fluorescent callose signals were induced by $\mathrm{HrpN}_{\mathrm{Pcc}}$. In addition, more abundant $\mathrm{HrpN}_{\mathrm{Pcc}}$-mediated callose deposition was observed in the treatments with $B$. amyloliquefaciens strain PMB03 or strain PMB05 than in the treatments with the other Bacillus spp. strains (Fig. 8A). Compared with the treatment with $\mathrm{HrpN}_{\mathrm{Pcc}}$ alone, the $\mathrm{HrpN}_{\text {Pcc }}$-triggered fluorescent intensity was increased by 4.6- and 8.2-fold in the treatment with B. amyloliquefaciens strains PMB03 and PMB05, respectively. In contrast, the intensities of $\mathrm{HrpN}_{\mathrm{Pcc}}$-mediated callose deposition in the treatments with the other Bacillus spp. strains did not show significant increases in comparison with that of treatment $\mathrm{HrpN}_{\mathrm{Pcc}}$ alone (Fig. 8B).

Effects of Bacillus spp. strains on disease resistance to bacterial soft rot. To assess whether the B. amyloliquefaciens strains PMB03 and PMB05 intensified the resistance to bacterial soft rot disease, the disease severities caused by $P$. carotovorum subsp. carotovorum were evaluated in Arabidopsis plants. The results showed that the disease severity was reduced from 82.2 to 27.9 and $35.5 \%$ by B. amyloliquefaciens strains PMB03 and PMB05, respectively (Fig. 9). In contrast, the disease severities of bacterial soft rot were not reduced by the treatments with Bacillus spp. strains PMB04, DR81, DR237, DR243, DR244, or DR258.
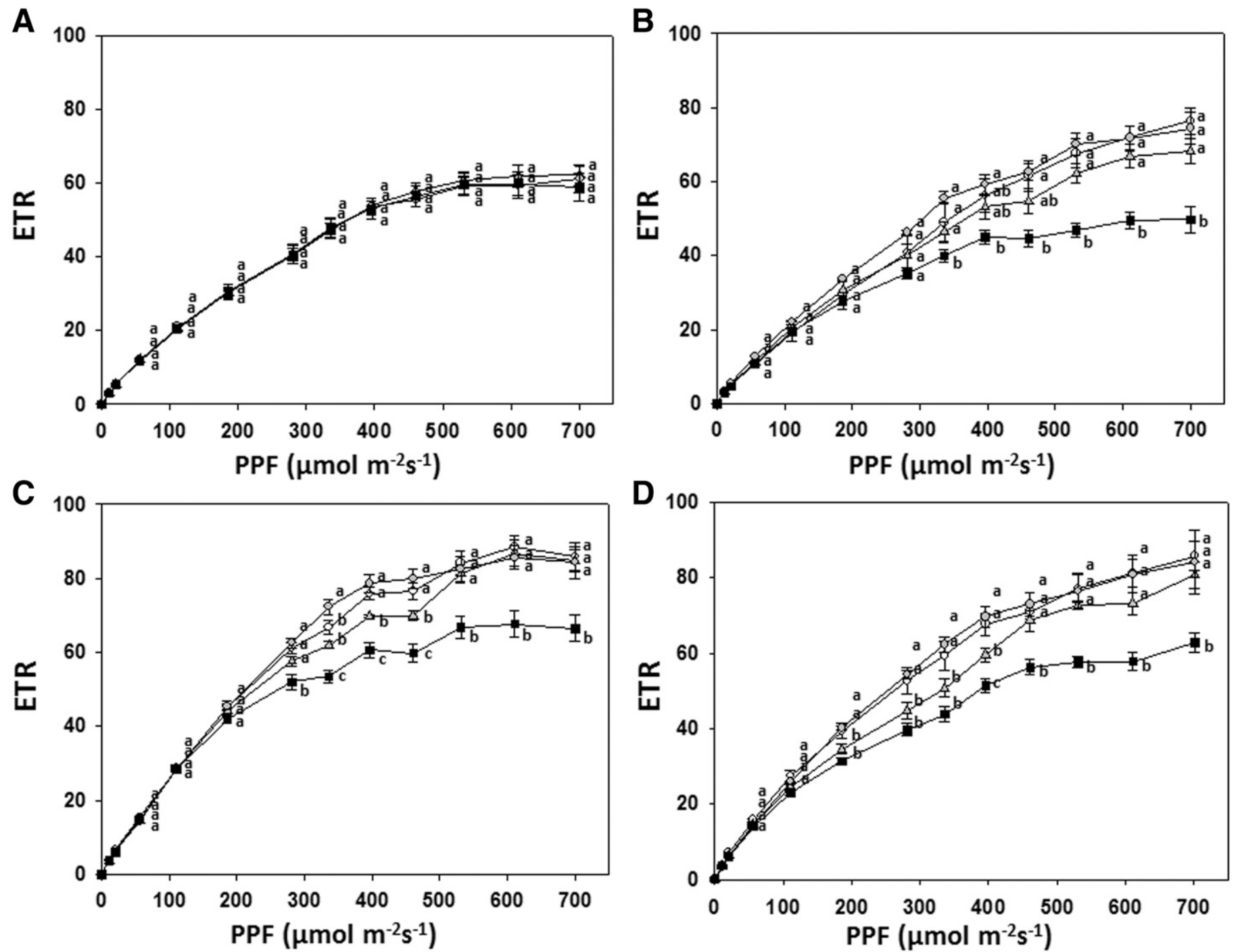

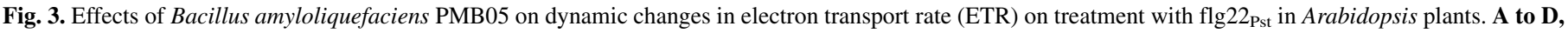

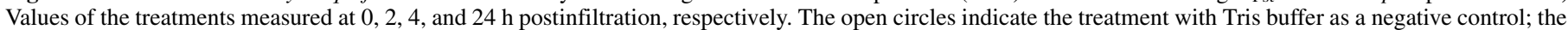

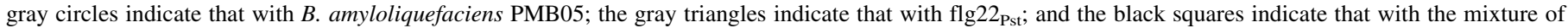

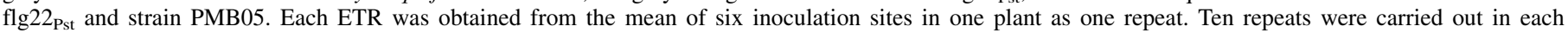

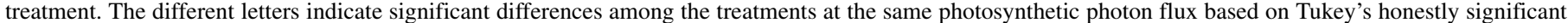
difference test $(P<0.05)$. 


\section{DISCUSSION}

Given the need to protect plants against various diseases, the development of effective and safe control strategies has become increasingly important. A number of control strategies based on the intensification of innate plant immunity by PFLP or beneficial microorganisms aimed at controlling various plant diseases have been demonstrated recently (Ger et al. 2014; Huang et al. 2004, 2006; Liau et al. 2003; Lin et al. 2011; Namukwaya et al. 2012; Su et al. 2014).

Previous studies have reported that PFLP intensifies signal transduction in the mitogen-associated protein kinase (MAPK) pathways of PTI to further enhance disease resistance to bacterial soft rot (Hong et al. 2018). Our own previous studies have further demonstrated that B. amyloliquefaciens strain PMB05 intensifies PTI such that cabbage becomes resistant to bacterial black rot disease (Li'aini et al. 2017). In the past, it was not possible to demonstrate the effect of such strains on PTI by analyzing the signals for the initiation of the defense response, such as rapid ROS generation and callose deposition, in a manner that was not invasive and destructive of the leaves (Hong et al. 2018; Lu et al. 2011; Luna et al. 2011). Recently, however, a nondestructive analytic method based on chlorophyll fluorescence found that such fluorescence was associated with the activation of PTI triggered by flg22. Specifically, treatment with flg22 causes a reduction in nonphotochemical quenching $\left(\mathrm{Y}_{(\mathrm{NPO})}\right)$ values at $2 \mathrm{~h}$ but not $4 \mathrm{~h}$ postinfiltration (Göhre et al. 2012). Although the results of the present study did not indicate a significant reduction in $\mathrm{Y}_{(\mathrm{NPQ})}$ caused by flg22 alone, $\mathrm{Y}_{(\mathrm{NPQ})}$ was strongly reduced by treatment with a mixture of flg22 $2_{\text {Pst }}$ and PFLP (Fig. 2) or by treatment with B. amyloliquefaciens strain PMB05 at $24 \mathrm{~h}$ postinfiltration (Fig. 4). We also observed that PMB05 increased the $\mathrm{Y}_{(\mathrm{NPQ})}$ on treatment with flg22 $2_{\mathrm{Pst}}$ at $2 \mathrm{~h}$ postinfiltration, a result that suggested the application of PMB05 reduced the light inhibition and increased the light protection mechanisms of the photosynthetic system at the beginning of PTI activation. In the analysis of ETR values, our results showed that treatment with flg $22_{\mathrm{Pst}}$ alone did not result in a significant reduction within $24 \mathrm{~h}$ postinfiltration. However, PFLP or strain PMB05 caused dramatic reductions in the ETR under higher light levels on flg22-triggered responses at 2, 4, and $24 \mathrm{~h}$ postinfiltration. These results suggested that the reduction in the light protection and electron transfer efficiency of the photosynthetic system may occur with the initial steps of PTI activation. Such a dramatic reduction in the ETR also has been demonstrated in the infiltration of Pseudomonas syringae avirulent strain rather than virulent strain on Arabidopsis leaves at $3 \mathrm{~h}$ (Bonfig et al. 2006). This
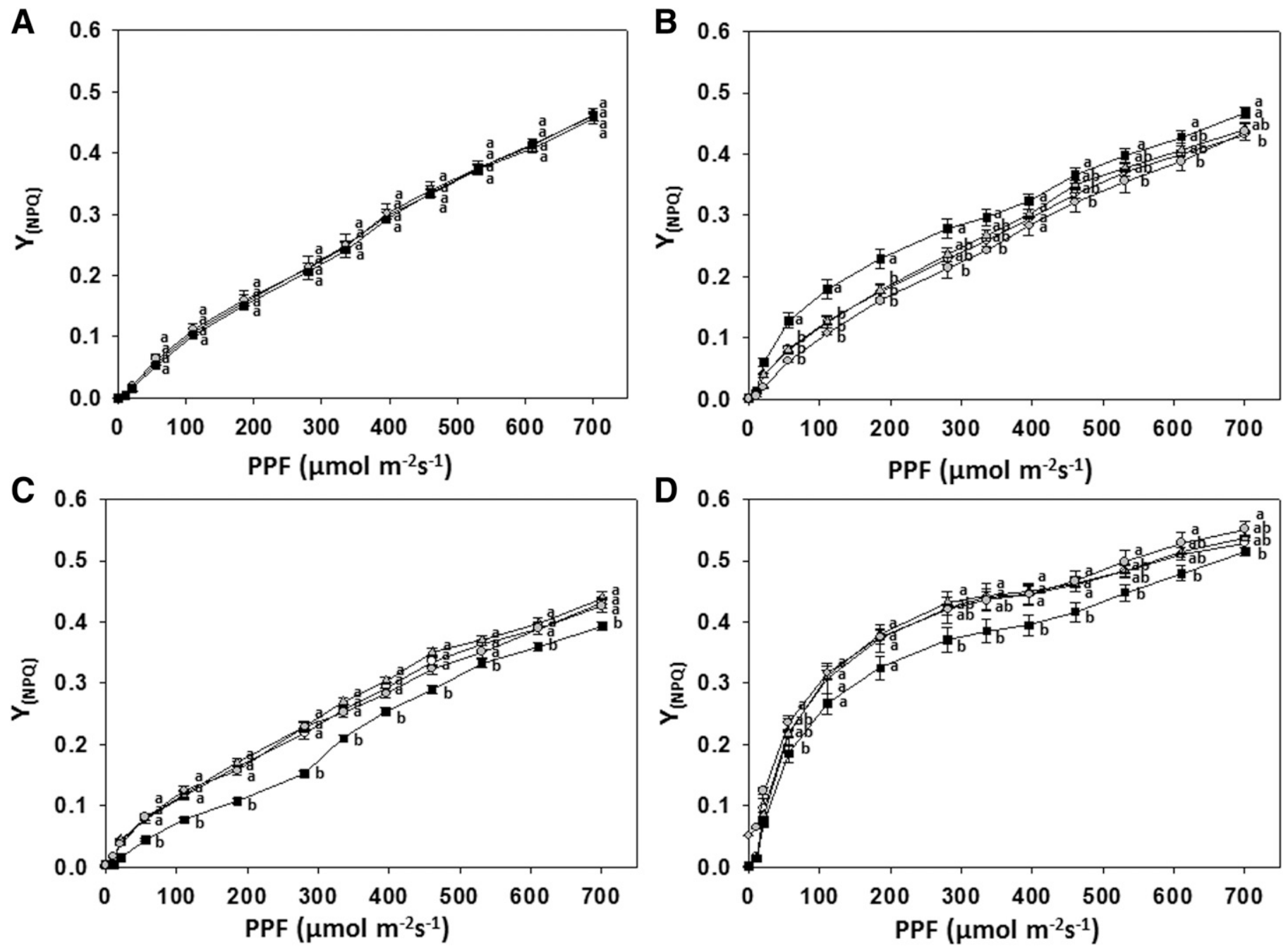

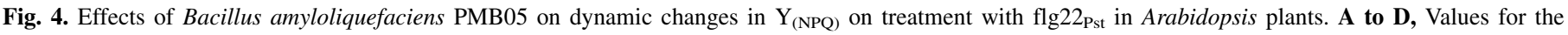

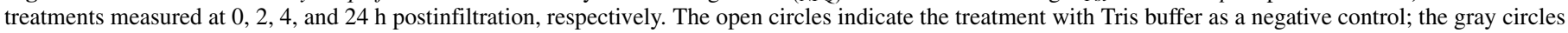

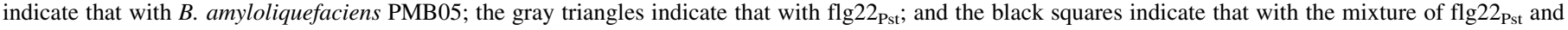

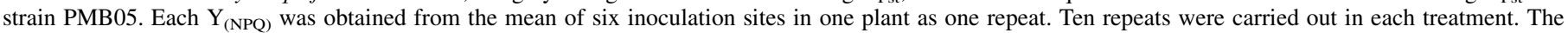

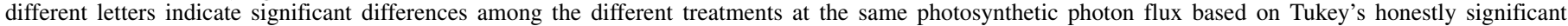
difference test $(P<0.05)$. 
A

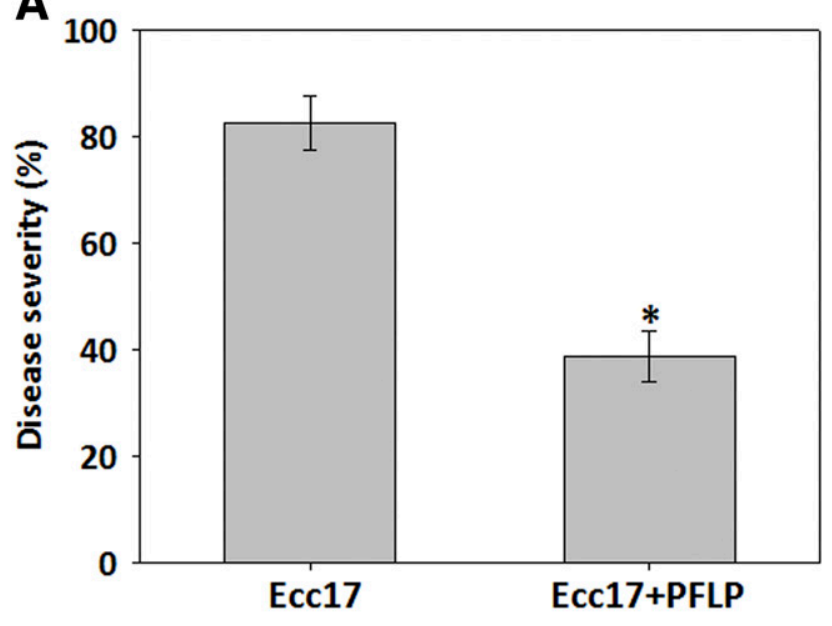

B

Ecc17
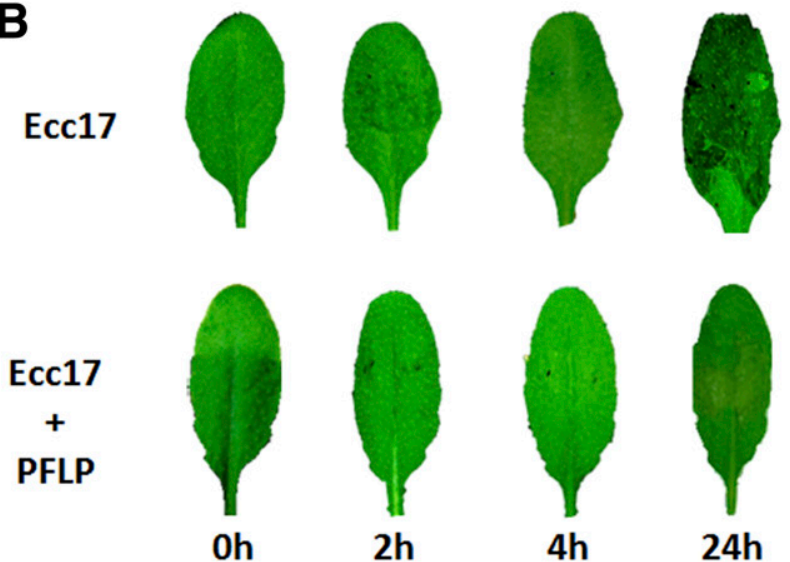

C

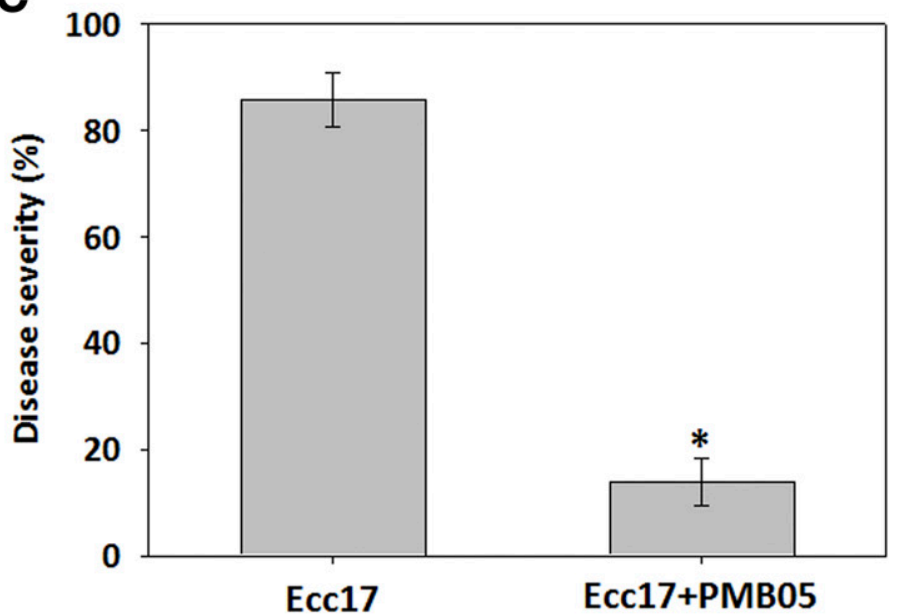

D

\section{Ecc17}
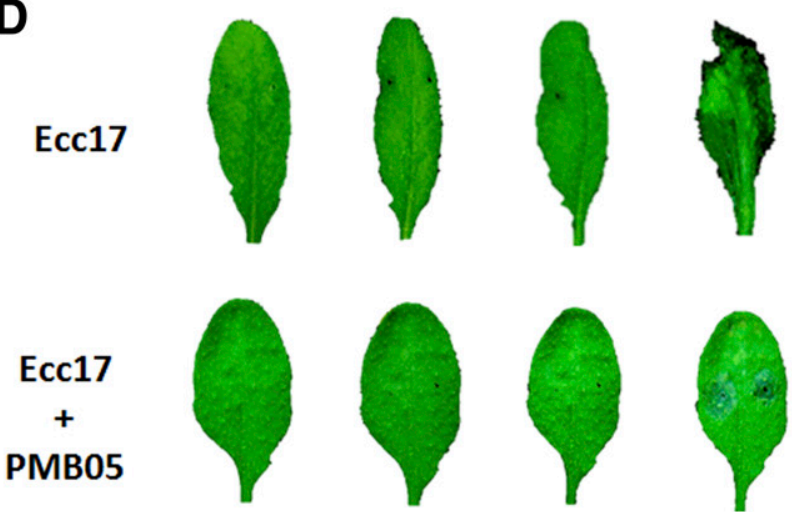

Oh

2h

4h

24h

Fig. 5. Effects of plant ferredoxin-like protein (PFLP) or Bacillus amyloliquefaciens PMB05 on disease resistance against bacterial soft rot in Arabidopsis plants. A and C, The disease severity observed with the coinfiltration of Pectobacterium carotovorum subsp. carotovorum strain Ecc17 at $10^{6}$ CFU/ml and PFLP recombinant protein at $1 \mathrm{mg} / \mathrm{ml}$ or B. amyloliquefaciens PMB05 at $10^{8} \mathrm{CFU} / \mathrm{ml}$ in 4-week-old leaves. The disease severities were calculated from the index of five leaves at $24 \mathrm{~h}$ postinfiltration as one repeat. Three repeats were carried out in each treatment. The asterisks indicate significant differences compared with the inoculation performed with strain Ecc17 alone based on the $t$ test $(P<0.05)$. B and D, Symptoms observed at 0 , 2, 4, and $24 \mathrm{~h}$ postinfiltration.

A

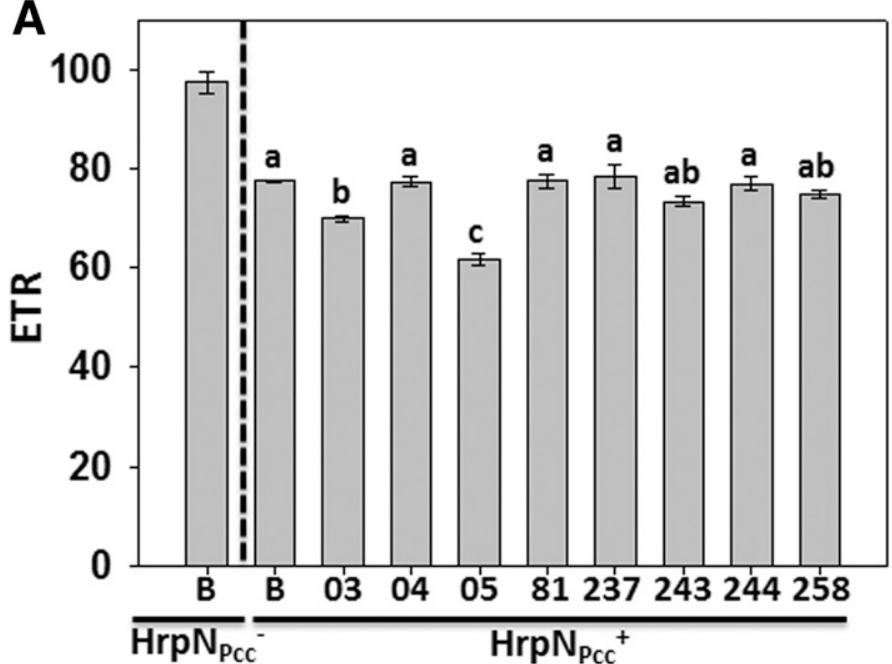

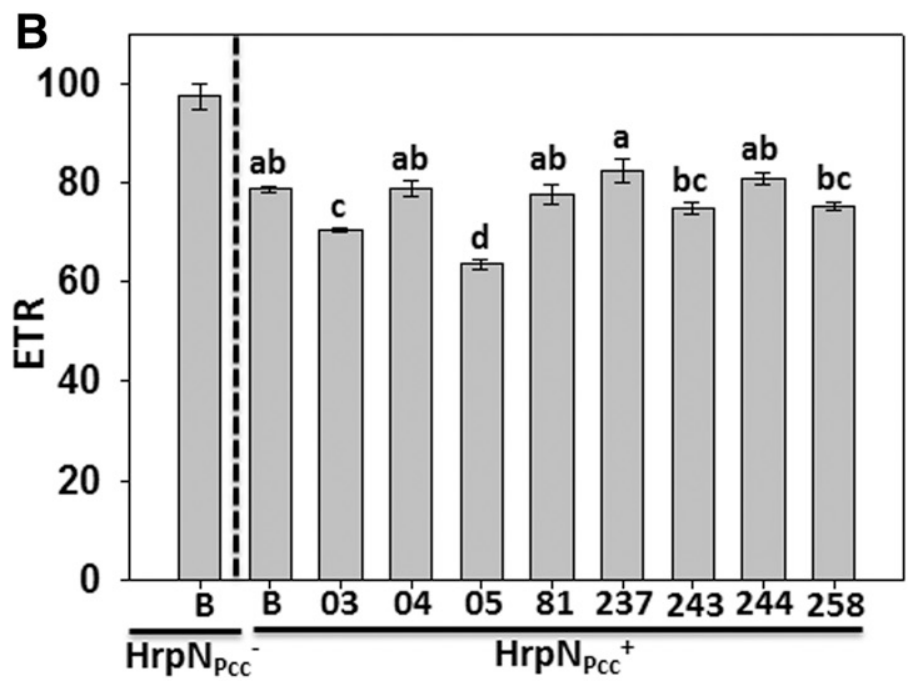

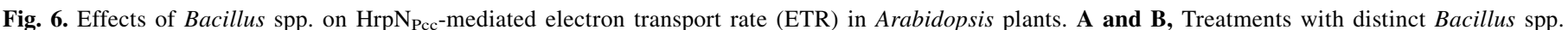

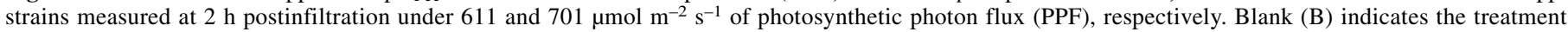

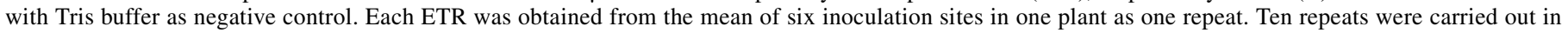

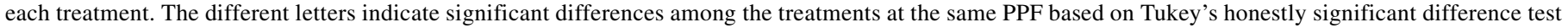
$(P<0.05)$. 
result indicates the ETR reduction occurs during the activation of effector-triggered immunity. And, their results may suggest the initial activation of PTI by a virulent strain does not achieve the threshold of defense amplitude to lead to ETR alteration. It is also suggested that the occurrence of PTI does affect the ETR of photosynthesis and that the ETR can be used as an index to evaluate the intensification of PTI by recombinant proteins or microorganisms within $2 \mathrm{~h}$. The reductions in the ETR of $A$. thaliana are similar to the intensification of PTI induced by PFLP in the presence of flg22 (Hong et al. 2018; Su et al. 2014). Compared with values of $\mathrm{Y}_{(\mathrm{NPQ})}, \mathrm{Y}_{(\mathrm{NO})}$, and ETR, ETR is best echoed to the intensifying signals on PTI. It is because the calculation of ETR is based on the

A

Blank

PMB03

PMB04

PMB05

DR81
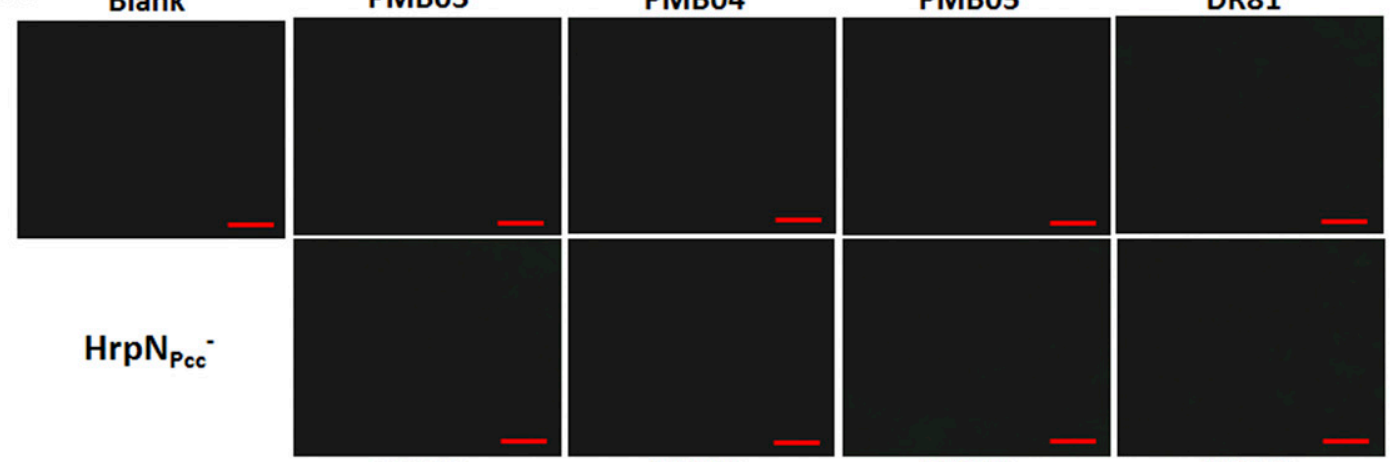

DR237

DR243

DR244

DR258

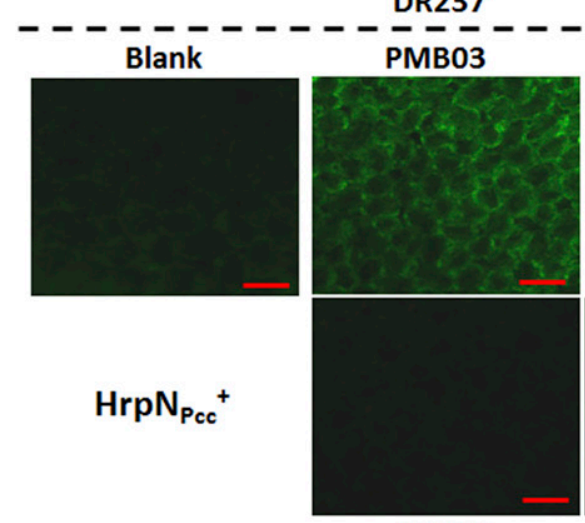

DR237
PMB04

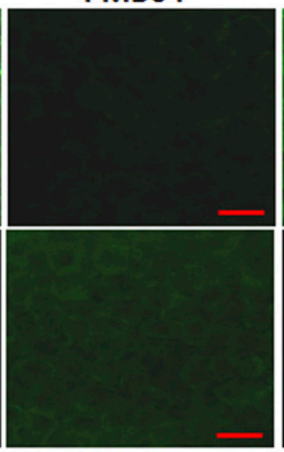

DR243
PMB05

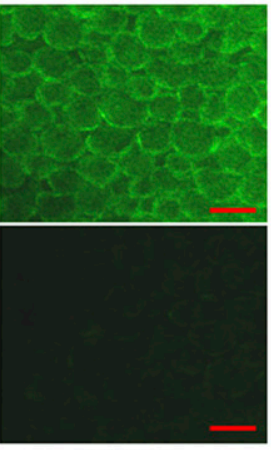

DR244
DR81

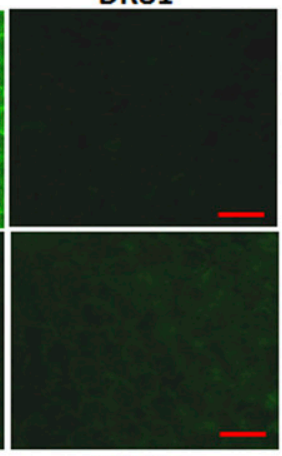

DR258

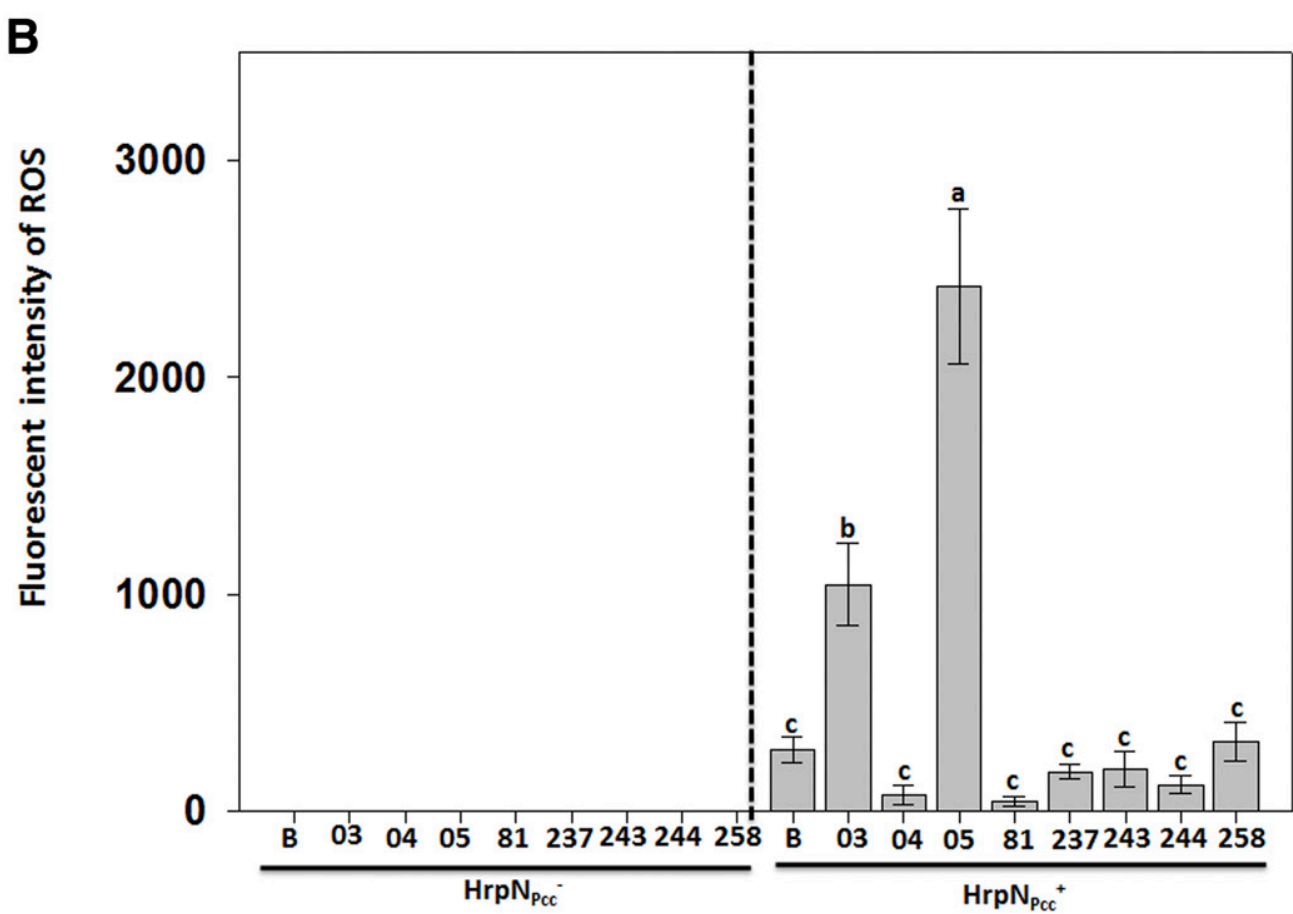

Fig. 7. Effects of Bacillus spp. strains on rapid $\mathrm{H}_{2} \mathrm{O}_{2}$ generation on treatment with $\mathrm{HrpN}_{\mathrm{Pcc}}$ in Arabidopsis plants. A, The images of infiltrated leaves stained with $20 \mu \mathrm{M} \mathrm{H}_{2}$ DCFDA at $1 \mathrm{~h}$ postinfiltration to observe rapid $\mathrm{H}_{2} \mathrm{O}_{2}$ generation. Each bar indicates $20 \mu \mathrm{m}$ in length. B, The fluorescent intensity of $\mathrm{H}_{2} \mathrm{O}_{2}$ generated by the treatments in infiltrated leaves measured by Image J. The different letters indicate significant differences between the treatments based on Tukey's honestly significant difference test $(P<0.05)$. 
PPF, the higher PPF would expand more differences to observe the changes on photosynthetic efficiency. We may further suggest this amplification effect of ETR helps to evaluate the PTI intensification during the initiation of HR cell death. Moreover, the disease severities of bacterial soft rot were found to be significantly reduced by PFLP or B. amyloliquefaciens strain PMB05 in our assays. Therefore, we suggest that the reductions in the ETR were consistent with the intensification of PTI triggered by flg22 $2_{\mathrm{Pst}}$ and the disease resistance to bacterial soft rot triggered by PFLP or B. amyloliquefaciens strain PMB05.

PTI is an innate plant defense response triggered by the recognition of PAMPs on the plasma membrane of a plant (Dodds and Rathjen 2010). Bacterial PAMPs, such as harpin, flagellin, peptidoglycan, and elongation factor Tu, are identified by distinct
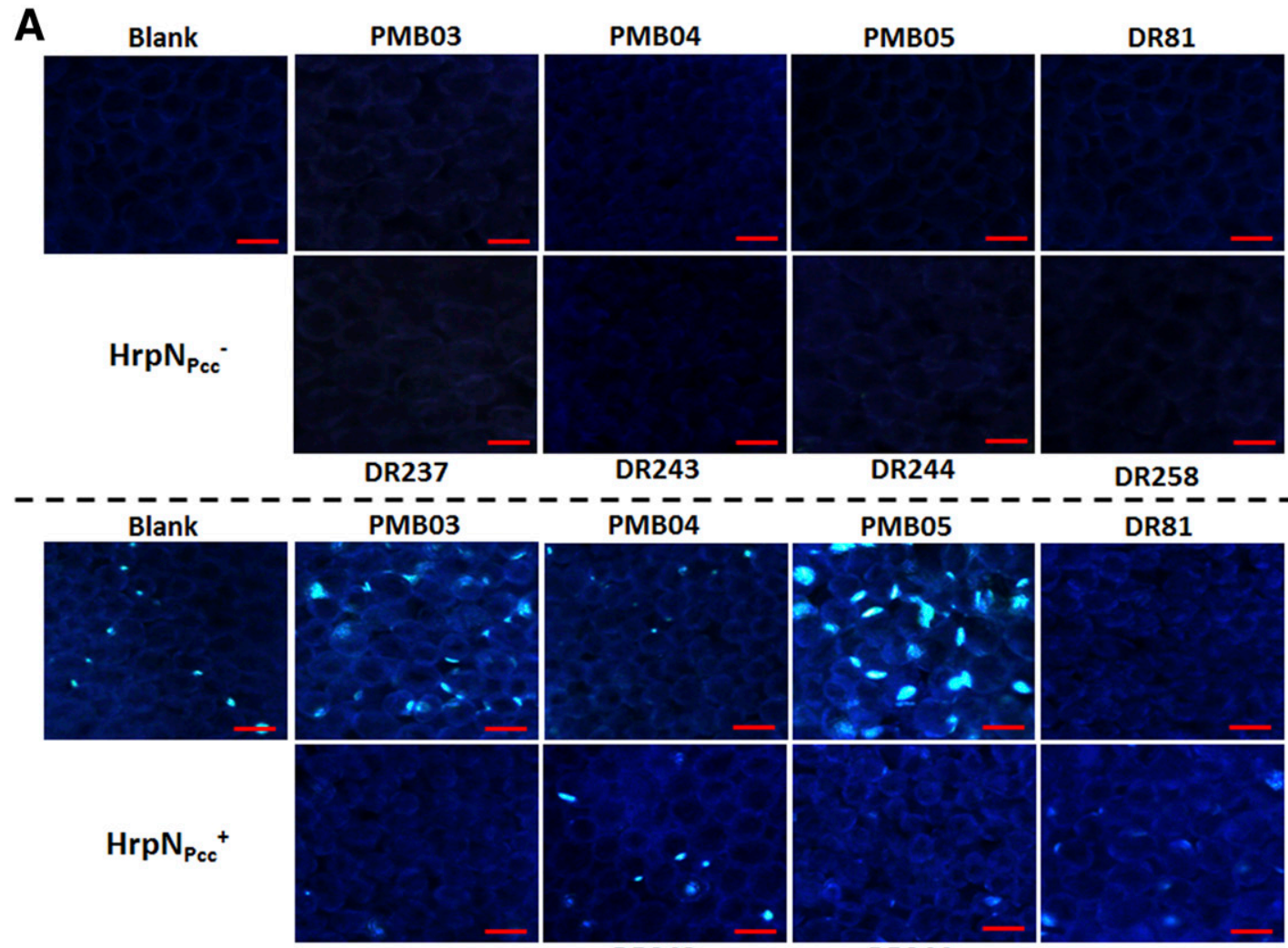

DR244

DR258

DR237

PMB04

PMB05
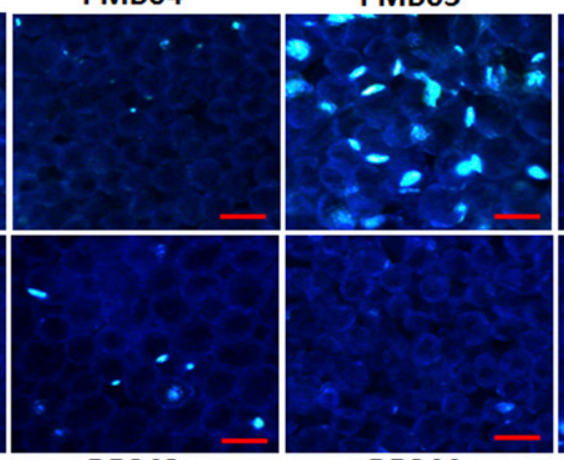

DR81

B

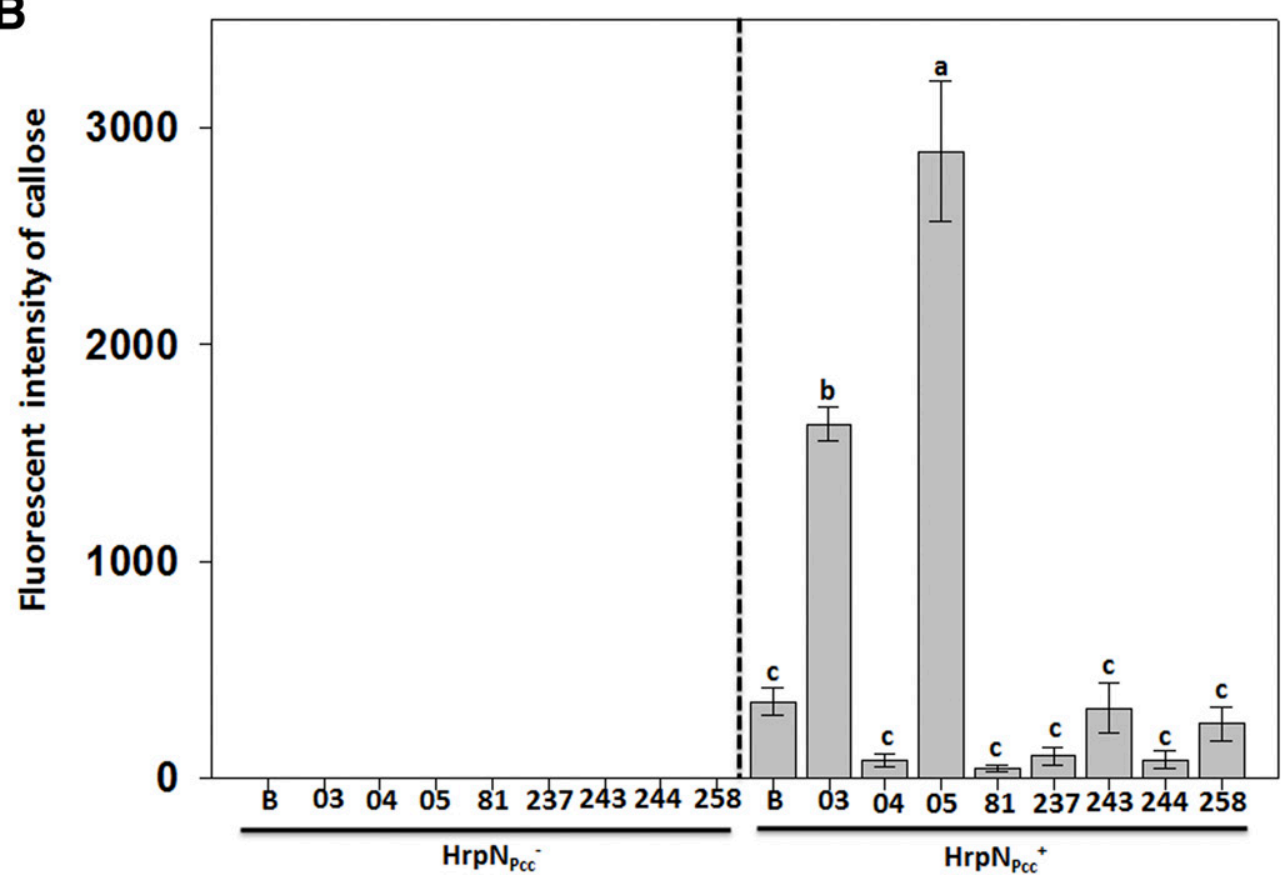

Fig. 8. Effects of Bacillus spp. strains on callose deposition on treatment with $\mathrm{HrpN}_{\mathrm{Pcc}}$ in Arabidopsis plants. A, Images of infiltrated leaves stained with 0.01\% aniline blue at $8 \mathrm{~h}$ postinfiltration to observe callose deposition. Each bar indicates $20 \mu \mathrm{m}$ in length. B, Fluorescent intensity of callose signals in infiltrated leaves measured by Image J. The different letters indicate significant differences between the treatments based on Tukey's honestly significant difference test $(P<0.05)$. 
specific receptors that activate defense signals (Gust et al. 2007; Postel and Kemmerling 2009). In this study, to further validate the interaction of PTI activation and ETR reduction in the presence of Bacillus spp. strains, $\mathrm{HrpN}_{\mathrm{Pcc}}$ from $P$. carotovorum subsp. carotovorum and Bacillus spp. strains were used to assay the effects of those strains on the ETR, rapid $\mathrm{H}_{2} \mathrm{O}_{2}$ generation, callose deposition, and disease resistance. The results showed that the $\mathrm{HrpN}_{\text {Pcc }}$-mediated ETR was significantly reduced under light levels of 611 and $701 \mu \mathrm{mol} \mathrm{m} \mathrm{m}^{-2} \mathrm{~s}^{-1}$ of PPF at $2 \mathrm{~h}$ postinfiltration. This result not only confirms that the activation of PTI and ETR reductions occurred simultaneously but also exhibits that $\mathrm{HrpN}_{\mathrm{Pcc}}$ triggers stronger ETR reductions than flg22 Pst. Among eight Bacillus spp. strains, we found that the B. subtilis strain PMB03 and the $B$. amyloliquefaciens strain PMB05 strain reduced the $\mathrm{HrpN}_{\text {Pcc }}$-mediated ETR under two different light levels. Meanwhile, the $\mathrm{HrpN}_{\mathrm{Pcc}}$-mediated PTI signals and disease resistance to bacterial soft rot were intensified by these two strains. In addition, the other strains, which did not reduce the $\mathrm{HrpN}_{\mathrm{Pcc}}$-mediated ETR, also did not increase the PTI signals or disease resistance. Therefore, we suggest that the $\mathrm{HrpN}_{\mathrm{Pcc}}$-mediated ETR under the light levels of 611 and $701 \mu \mathrm{mol} \mathrm{m} \mathrm{m}^{-2} \mathrm{~s}^{-1}$ would provide an effective means of evaluating the effects of PTI-intensifying microorganisms at $2 \mathrm{~h}$ postinfiltration. In addition to the finding that the $\mathrm{HrpN}_{\mathrm{Pcc}^{-}}$ mediated ETR reduction, rapid ROS generation and callose deposition caused by PMB05 was stronger than that caused by PMB03, it also should be noted these two strains exhibited equal effects in terms of enhancing the disease resistance to bacterial soft rot. The inhibitory effect assay revealed that PMB03 had a stronger antagonistic effect than PMB05. Based on this result, we speculated that the selection of microorganisms based on their antagonistic effects would provide PTI-intensifying microorganisms with superior effectiveness for plant disease control.

Taken together, the results of the PAMP-mediated ETR evaluation system based on chlorophyll fluorescence established in this study indicate that the system could serve as a model for determining whether a microbe is able to intensify PTI. This system

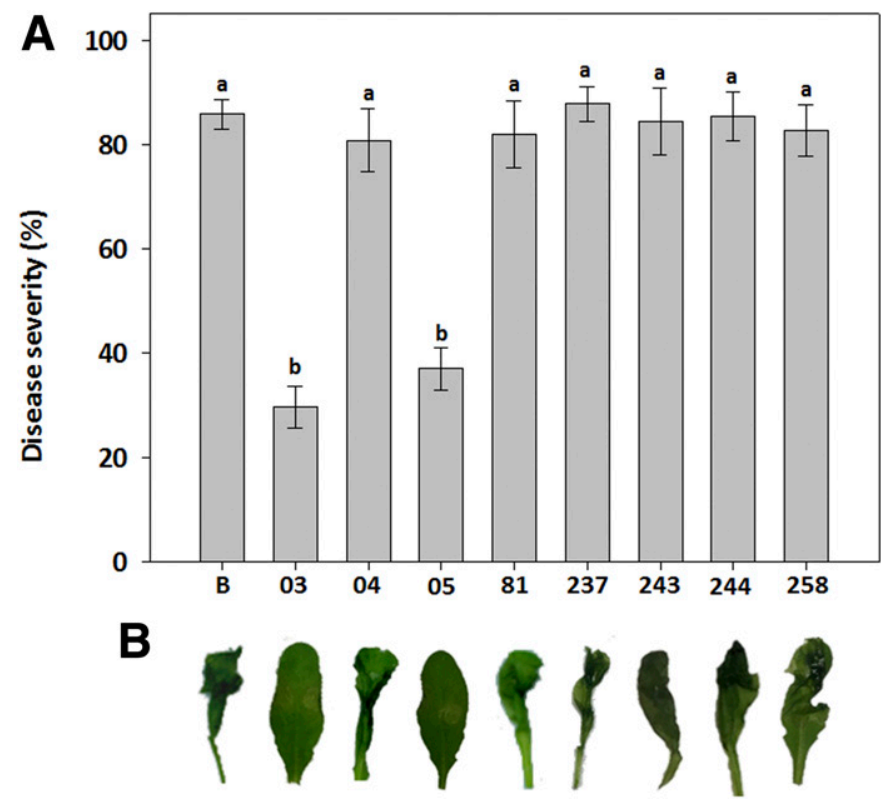

Fig. 9. Effects of Bacillus spp. strains on disease resistance to bacterial soft rot in Arabidopsis plants. A, Disease severities elicited by the coinfiltration of Pectobacterium carotovorum subsp. carotovorum strain Ecc17 at $10^{6} \mathrm{CFU} / \mathrm{ml}$ and distinct Bacillus. spp. strains at $10^{8} \mathrm{CFU} / \mathrm{ml}$ in 4 -week-old leaves. The disease severities were calculated from the index of five leaves at $24 \mathrm{~h}$ postinfiltration as one repeat. Three repeats were carried out in each treatment. The different letters indicate significant differences between the treatments based on Tukey's honestly significant difference test $(P<0.05)$. B, Symptoms appearance of infiltrated leaves observed at $24 \mathrm{~h}$ postinfiltration. could be used to measure PTI signals directly without requiring the dark adaption or destruction of leaves. The system thus offers a promising approach for screening PTI-intensifying microbes for plant disease control in the future.

\section{LITERATURE CITED}

Asada, K. 1999. The Water-Water cycle in chloroplasts: Scavenging of active oxygens and dissipation of excess photons. Annu. Rev. Plant Physiol. Plant Mol. Biol. 50:601-639.

Bonfig, K. B., Schreiber, U., Gabler, A., Roitsch, T., and Berger, S. 2006. Infection with virulent and avirulent $P$. syringae strains differentially affects photosynthesis and sink metabolism in Arabidopsis leaves. Planta 225:1-12.

Cornic, G., and Baker, N. R. 2012. Electron transport in leaves: A physiological perspective. Pages 591-605 in: Advances in Photosynthesis and Respiration: Photosynthesis: Plastid Biology, Energy Conversion and Carbon Assimilation. J. Eaton-Rye, B. Tripathy, and T. Sharkey, eds. Springer, Dordrecht, The Netherlands.

Dodds, P. N., and Rathjen, J. P. 2010. Plant immunity: Towards an integrated view of plant-pathogen interactions. Nat. Rev. Genet. 11:539-548.

Ehleringer, J. 1981. Leaf absorptances of Mohave and Sonoran desert plants. Oecologia 49:366-370.

Felix, G., Duran, J. D., Volko, S., and Boller, T. 1999. Plants have a sensitive perception system for the most conserved domain of bacterial flagellin. Plant J. 18:265-276.

Genty, B., Briantais, J.-M., and Baker, N. R. 1989. The relationship between the quantum yield of photosynthetic electron transport and quenching of chlorophyll fluorescence. Biochim. Biophys. Acta 990:87-92.

Ger, M.-J., Louh, G.-Y., Lin, Y.-H., Feng, T.-Y., and Huang, H.-E. 2014. Ectopic expressed sweet pepper ferredoxin PFLP enhances disease resistance to Pectobacterium carotovorum subsp. carotovorum affected by harpin and protease-mediated hypersensitive response in Arabidopsis. Mol. Plant Pathol. 15:892-906. doi.org/10.1111/mpp.12150

Göhre, V., Jones, A. M., Sklenář, J., Robatzek, S., and Weber, A. P. 2012. Molecular crosstalk between PAMP-triggered immunity and photosynthesis. Mol. Plant-Microbe Interact. 25:1083-1092.

Gust, A. A., Biswas, R., Lenz, H. D., Rauhut, T., Ranf, S., Kemmerling, B., Götz, F., Glawischnig, E., Lee, J., Felix, G., and Nürnberger, T. 2007. Bacteria-derived peptidoglycans constitute pathogen-associated molecular patterns triggering innate immunity in Arabidopsis. J. Biol. Chem. 282: 32338-32348.

Hong, C.-Y., Zheng, J.-L., Chen, T.-Y., Chao, H.-R., and Lin, Y.-H. 2018. PFLPintensified disease resistance against bacterial soft rot through MAPK pathway in PAMP-triggered immunity. Phytopathology 108:1467-1474.

Huang, H.-E., Ger, M.-J., Chen, C.-Y., Pandey, A.-K., Yip, M.-K., Chou, H.-W., and Feng, T.-Y. 2007. Disease resistance to bacterial pathogens affected by the amount of ferredoxin-I protein in plants. Mol. Plant Pathol. 8:129-137.

Huang, H.-E., Ger, M.-J., Chen, C.-Y., Yip, M.-K., Chung, M.-C., and Feng, T.-Y. 2006. Plant ferredoxin-like protein (PFLP) exhibits an anti-microbial ability against soft-rot pathogen Erwinia carotovora subsp. carotovora in vitro and in vivo. Plant Sci. 171:17-23.

Huang, H.-E., Ger, M.-J., Yip, M.-K., Chen, C.-Y., Pandeya, A.-K., and Feng, T.-Y. 2004. A hypersensitive response was induced by virulent bacteria in transgenic tobacco plants overexpressing a plant ferredoxin-like protein (PFLP). Physiol. Mol. Plant Pathol. 64:103-110.

Kariola, T., Palomäki, T. A., Brader, G., and Palva, E. T. 2003. Erwinia carotovora subsp. carotovora and Erwinia-derived elicitors HrpN and PehA trigger distinct but interacting defense responses and cell death in Arabidopsis. Mol. Plant-Microbe Interact. 16:179-187.

Klughammer, C., and Schreiber, U. 2008. Complementary PS II quantum yields calculated from simple fluorescence parameters measured by PAM fluorometry and the Saturation Pulse method. PAM Appl. Notes 1:27-35.

Kramer, D. M., Johnson, G., Kiirats, O., and Edwards, G. E. 2004. New fluorescence parameters for the determination of $\mathrm{Q}_{\mathrm{A}}$ redox state and excitation energy fluxes. Photosynth. Res. 79:209-218.

Lamb, C., and Dixon, R. A. 1997. The oxidative burst in plant disease resistance. Annu. Rev. Plant Physiol. Plant Mol. Biol. 48:251-275.

Li'aini, A. S., Lin, Y.-H., Huang, T.-C., and Sulistyowati, L. 2017. Application of Bacillus amyloliquefaciens to control black rot disease on cabbage caused by Xanthomonas campestris pv. campestris. J. Plant Med. 59:39-44.

Liau, C.-H., Lu, J.-C., Prasad, V., Hsiao, H.-H., You, S.-J., Lee, J.-T., Yang, N.-S., Huang, H.-E., Feng, T.-Y., Chen, W.-H., and Chan, M.-T. 2003. The sweet pepper ferredoxin-like protein ( $p f l p$ ) conferred resistance against soft rot disease in Oncidium orchid. Transgenic Res. 12:329-336.

Lin, Y.-H., Huang, H.-E., Chen, Y.-R., Liao, P.-L., Chen, C.-L., and Feng, T.-Y. 2011. C-terminal region of plant ferredoxin-like protein is required to enhance resistance to bacterial disease in Arabidopsis thaliana. Phytopathology 101:741-749. 
Lu, D., Lin, W., Gao, X., Wu, S., Cheng, C., Avila, J., Heese, A., Devarenne, T. P., He, P., and Shan, L. 2011. Direct ubiquitination of pattern recognition receptor FLS2 attenuates plant innate immunity. Science 332:1439-1442.

Luna, E., Pastor, V., Robert, J., Flors, V., Mauch-Mani, B., and Ton, J. 2011. Callose deposition: A multifaceted plant defense response. Mol. PlantMicrobe Interact. 24:183-193.

Namukwaya, B., Tripathi, L., Tripathi, J. N., Arinaitwe, G., Mukasa, S. B., and Tushemereirwe, W. K. 2012. Transgenic banana expressing pflp gene confers enhanced resistance to Xanthomonas wilt disease. Transgenic Res. 21:855-865.

Nie, P., Li, X., Wang, S., Guo, J., Zhao, H., and Niu, D. 2017. Induced systemic resistance against Botrytis cinerea by Bacillus cereus AR156 through a JA/ET- and NPRl-dependent signaling pathway and activates PAMP-triggered immunity in Arabidopsis. Front. Plant Sci. 8:238.

Nomura, H., Komori, T., Uemura, S., Kanda, Y., Shimotani, K., Nakai, K., Furuichi, T., Takebayashi, K., Sugimoto, T., Sano, S., Suwastika, I. N., Fukusaki, E., Yoshioka, H., Nakahira, Y., and Shiina, T. 2012. Chloroplastmediated activation of plant immune signalling in Arabidopsis. Nat. Commun. 3:926.

Postel, S., and Kemmerling, B. 2009. Plant systems for recognition of pathogenassociated molecular patterns. Semin. Cell Dev. Biol. 20:1025-1031.

Rasband, W. S. 1997-2016. ImageJ. U.S. National Institutes of Health, Bethesda, MD. https://imagej.nih.gov/ij/
Sierla, M., Rahikainen, M., Salojärvi, J., Kangasjärvi, J., and Kangasjärvi, S. 2013. Apoplastic and chloroplastic redox signaling networks in plant stress responses. Antioxid. Redox Signal. 18:2220-2239.

Song, X., Zhou, G., Xu, Z., Lv, X., and Wang, Y. 2016. Detection of photosynthetic performance of Stipa bungeana seedlings under climatic change using chlorophyll fluorescence imaging. Front. Plant Sci. 6:1254.

Su, Y.-H., Hong, C.-Y., and Lin, Y.-H. 2014. Plant ferredoxin-like protein enhances resistance to bacterial soft rot disease through PAMP-triggered immunity in Arabidopsis thaliana. Eur. J. Plant Pathol. 140:377-384.

Tang, K. X., Sun, X. F., Hu, Q. N., Wu, A. Z., Lin, C. H., Lin, H.-J., Twyman, R. M., Christou, P., and Feng, T.-Y. 2001. Trangenic rice plants expressing the ferredoxin-like proein (AP1) from sweet pepper show enhanced resistance to Xanthomonas oryzae pv. oryzae. Plant Sci. 160:1035-1042.

Xu, Z. Z., and Zhou, G. S. 2006. Combined effects of water stress and high temperature on photosynthesis, nitrogen metabolism and lipid peroxidation of a perennial grass Leymus chinensis. Planta 224:1080-1090.

Yip, M.-K., Huang, H.-E., Ger, M.-J., Chiu, S.-H., Tsai, Y.-C., Lin, C.-I., and Feng, T.-Y. 2007. Production of soft rot resistant calla lily by expressing a ferredoxin-like protein gene (pflp) in transgenic plants. Plant Cell Rep. 26: 449-457.

Yip, M.-K., Lee, S.-W., Su, K.-C., Lin, Y.-H., Chen, T.-Y., and Feng, T. Y. 2011. An easy and efficient protocol in the production of pflp transgenic banana against Fusarium wilt. Plant Biotechnol. Rep. 5:245-254. 